\title{
Developing an e-learning course on the use of PRO measures in oncological practice: health care professionals' preferences for learning content and methods
}

\author{
Monika Sztankay ${ }^{1}$ (1) - Lisa M. Wintner ${ }^{1} \cdot$ Sigrid Roggendorf $^{3} \cdot$ Thomas Nordhausen $^{3} \cdot$ Linda Dirven $^{4,5}$. \\ Martin J. B. Taphoorn ${ }^{4,5} \cdot$ Irma M. Verdonck-de Leeuw ${ }^{6,7} \cdot$ Galina Velikova $^{8,9} \cdot$ Andrew Bottomley $^{10} \cdot$ Dagmara Kulis $^{10}$. \\ Timo Kachel ${ }^{2} \cdot$ Heike Schmidt $^{3,11}$ - on behalf of the EORTC Quality of Life Group
}

Received: 16 July 2021 / Accepted: 1 November 2021 / Published online: 19 November 2021

(c) The Author(s) 2021, corrected publication 2021

\begin{abstract}
Purpose Implementation of patient-reported outcome measures (PROMs) in clinical routine requires knowledge and competences regarding their use. In order to facilitate implementation, an e-learning course for health care professionals (HCPs) on the utilisation of European Organisation for Research and Treatment of Cancer (EORTC) PROMs in oncological clinical practice is being developed. This study aimed to explore future users' educational needs regarding content and learning methods.

Methods The sequential mixed methods approach was applied. A scoping literature review informed the guideline for qualitative interviews with HCPs with diverse professional backgrounds in oncology and cancer advocates recruited using a purposive sampling strategy. An international online survey was conducted to validate the qualitative findings.

Results Between December 2019 and May 2020, 73 interviews were conducted in 9 countries resulting in 8 topic areas (Basic information on PROs in clinical routine, Benefits of PRO assessments in clinical practice, Implementation of PRO assessments in clinical routine, Setup of PRO assessments for clinical application, Interpretation of PRO data, Integration of PROs into the communication with patients, Use of PROs in clinical practice, Self-management recommendations for patients based on PROs) subsequently presented in the online survey. The online survey (open between 3 June and 19 July 2020) was completed by $233 \mathrm{HCPs}$ from 33 countries. The highest preference was indicated for content on interpretation of PRO data (97\%), clinical benefits of assessing PRO data (95.3\%) and implementation of routine PRO data assessment (94.8\%). Regarding learning methods, participants indicated a high preference for practical examples that use a mixed approach of presentation (written, audio, video and interactive).

Conclusion Educational needs for an integration of PROs in communication in clinical care and coherent implementation strategies became evident. These results inform the development of an e-learning course to support HCPs in the clinical use of EORTC PRO measures.
\end{abstract}

Keywords Patient-reported outcome measures · Oncology $\cdot$ Quality of life $\cdot$ EORTC $\cdot$ e-learning $\cdot$ Distant learning · Implementation

\section{Introduction}

Patient-reported outcomes (PROs) provide important supplementary information on patients' subjective health status and symptom burden. A PRO, such as health-related

Monika Sztankay

monika.sztankay@tirol-kliniken.at

Extended author information available on the last page of the article quality of life (HRQOL), is a measurement of any aspect of a patient's health status that comes directly from the patient without the interpretation of the patient's responses by a physician or anyone else [1]. Evidence shows the value of integrating PROs into clinical practice to optimise symptom management, supportive therapy and patient-centred care and prolonged survival during oncological treatment [2-6]. Broad implementation into clinical routine, however, still remains a challenge, partly because of logistic and financial 
reasons as well as health care professionals' (HCPs) lack of familiarity with the concept [7].

To support implementation of PROMs into clinical practice, educational tools for HCPs are needed which include information about PROMs but also take the clinical realities of limited human resources, time and funding into account. Digital training tools, such as web-based e-learning courses, proved to be feasible alternatives to onsite training [8-10]. Though recommended for successful integration of PROMs into clinical practice [11], there is a gap in targeted, validated and multilingual education on this topic [12-15]. We aim to develop an e-learning course to support HCPs in the routine use of PRO assessments in clinical oncology practice, using the example of EORTC PRO instruments. The EORTC PRO measurement system comprises the EORTC QLQ-C30, which is a core questionnaire to assess HRQOL in cancer patients and can be supplemented with diseasespecific modules. To maximise levels of acceptance, a participatory approach is recommended during each stage of the developmental process, also regarding specific learning needs and training preferences [16].

This methodology goes in line with the recommended "contextual inquiries" of the holistic user-centred framework for the development of eHealth technologies, the "CeHRes Roadmap" [16-18]. Correspondingly, this study aimed to (1) explore the learning needs of oncological health care providers (with regard to course content and key issues on the implementation and use of PROMs in clinical practice) and (2) explore their preferences regarding e-learning methodology.

\section{Methods}

A mixed methods approach was applied in an exploratory sequential design. A scoping literature review (in preparation for publication) regarding available e-learning courses on PROMs in oncology informed the development of the qualitative interview guideline. Confirmation of the predefined framework on learning content was supported by a subsequent international anonymous online survey. Complementary to the ethical approval of the leading study centre, each participating centre adhered to the local requirements and obtained ethical approval if necessary.

\section{Qualitative semi-structured interviews}

Based on the results of the scoping review, a guideline for semi-structured interviews was developed (see supplementary material). In addition to open-ended questions, participants were asked to rate the relevance of predefined topics (i.e. concept/definition of PRO, available PRO measurement tools, choice of PRO measurement tools, timing and frequency of PRO assessments, choice of PRO measurement tools, interpretation of PRO scores, predefined examples of how to react to PRO data in clinical use and implementation issues) to be included in the course. Rating was performed on a Likert scale, from 1 (not at all relevant) to 4 (very much relevant).

Procedure Participants (including patient representatives, physicians, nurses, allied health professionals and IT specialists) were recruited via the professional networks of the collaborators, applying a purposeful critical case sampling method [19]. The interviews were conducted either face-to-face, online or via phone by the participating study collaborators. Depending on the interviewee's consent, the interviews were recorded and transcribed verbatim, or the interviewer took field notes during the interview.

Data analysis All participants received a centre-related pseudonym to protect their identity. To optimise data protection, the initial pseudonyms were recoded by the data management centre across the centres into consecutive IDs. The interview transcripts were analysed by a multi-professional research team, including physicians, psycho-oncologists and PRO researchers, applying an inductive-deductive content analysis following the approach outlined by Mayring [20]. According to the content elements of the interview guideline, an initial codebook was constructed to which quotations were deductively assigned. Content not suitable for any existing category was subsumed into inductively created new categories. Transcriptions were independently analysed and discussed by four researchers (HS, SR, LW, MS) until consensus was reached. Themes and subthemes were reviewed and refined until researchers agreed that these reflected the essence of the complete dataset. Supplementary material Table 2 provides quotes from participants to illustrate the categories and themes (Supplementary material Table 2 is available as supplementary material). The results of qualitative data analyses informed the design of the subsequent online survey.

\section{International online survey}

The international anonymous online survey was performed in order to confirm the relevance and complement the results of the interviews with a larger sample of the target group in various settings and countries. In addition, the survey aimed to assess educational needs and preferences regarding 
methods of presentation, to ensure generalisability of the e-learning course and applicability in different countries.

Sample The invitation to participate in the online survey was included in online newsletters/mailings from national and international professional associations (see "Acknowledgements") and disseminated by different sources of the EORTC (i.e. EORTC Quality of Life Department, EORTC Events Office via EORTC website and EORTC Headquarter social media accounts).

Procedure The anonymous online survey was set up via Lime Survey (http://www.limesurvey.org/). Participants were informed about the procedures of data collection, storage and protection. According to the results of the semi-structured interviews (part A), eight major topics for a possible modular structure of the e-learning course were presented in the online survey. Participants were asked to rate the relevance of the listed topics on a Likert scale (not a little - quite - very relevant) and to choose preferred methods of presentation for each topic from the provided options (e.g. visual, written, auditory). In addition, an open section for further comments and recommendations was provided.

Data analysis For the quantitative analyses, descriptive statistics (e.g. number and percentage) were applied via IBM SPSS Statistics 26. Qualitative data gained from comments in the open section were categorised according to the interview categories.

\section{Data integration}

Final data integration of qualitative and quantitative data was conducted after completion of the online survey, for which a joint display was used [21].

\section{Results}

\section{Sample description of the semi-structured interviews}

Between December 2019 and May 2020, 73 semi-structured interviews were conducted with participants from Austria $(n=20)$, The Netherlands $(n=21)$, Germany $(n=19)$, United Kingdom (UK; $n=7)$ and France, Belgium, Norway, Denmark, Israel and Malaysia $(n=1$ each), including physicians $(n=27)$, nurses $(n=21)$, psycho-oncologists $(n=10)$, patient representatives $(n=7)$,
IT specialists $(n=4)$ and other professions $(n=4)$. Four participants $(6 \%)$ were $<30$ years of age, 39 participants (53\%) were between 30 and 50 years of age, and $30(41 \%)$ were older than 50 years. Overall, $16.4 \%$ (12/73) of all participants indicated not having any kind of prior experience with PROs.

\section{Sample description of the online survey}

The international anonymous online survey was open between June 3 and July 19, 2020. The survey was completed by 233 HCPs from 33 countries, mainly aged between 30 and 50 years $(62.2 \%)$ and $52 \%$ female. The sample represents the intended target group of HCPs, of whom $28.3 \%$ (66/233) indicated not having prior experience with PRO assessments in clinical practice (see Table 1).

\section{Merged data analysis and data integration}

Qualitative analysis of the data assessed in the semi-structured interviews resulted in four main categories (A-D in Supplementary material Table 2) and ten subcategories (1-10 in Supplementary material file 2). A summary of categories and subcategories with representative quotes is presented in Supplementary material file 2. In the interviews, the embedded relevance ratings of the predefined themes showed highest ratings for basic knowledge on PROs (concept and definition) and self-management advice (95\%), how to communicate (89\%) and interpretation of PRO data and timing and frequency of assessments (88\%). The categories were merged into content clusters representing eight topic areas that were subsequently presented in the online survey. The analysis of the online survey confirmed the results of the interviews with respect to the suggested topics and methods of presentation (see additional quotes in Supplementary material file 2). The relevance of all 8 categories listed was rated $>90 \%$, with interpretation of PRO data $(226 / 233$, 97.0\%), clinical benefits of assessing PRO data (222/233, 95.3\%), implementation of routine PRO data assessment $(221 / 233,94.8 \%)$ and the use of PROMs and PRO data in clinical practice $(220 / 233,94.4 \%)$ receiving the highest relevance ratings (see Table 2). These were followed closely by basic information on PROs in clinical routine (219/233, 94\%).

Qualitative and quantitative findings of both methods are presented in a joint display (see Fig. 1). Table 2 provides a detailed summary on participants' ratings of relevance of suggested topics for the content and the methods of the e-learning course from both the semi-structured interviews and the online survey. On these findings, we based the final selection of topics for the learning content and structure and didactics of the e-learning programme, including methods of presentation (see Table 3). 
Table 1 Sociodemographic characteristics of participants in (a) semi-structured interviews $(n=73)$ and (b) online survey $(n=233)$

\begin{tabular}{|c|c|c|c|}
\hline \multicolumn{2}{|l|}{ Variable } & \multirow{2}{*}{$\begin{array}{l}\text { Interviews } \\
n(\%) \\
29(39.7)\end{array}$} & \multirow{2}{*}{$\begin{array}{l}\text { Online survey } \\
n(\%)\end{array}$} \\
\hline Sex & Male & & \\
\hline & Female & $44(60.3)$ & $122(52.4)$ \\
\hline \multirow[t]{3}{*}{ Age group } & $<30$ years & $4(5.5)$ & $3(1.3)$ \\
\hline & $30-50$ years & $39(53.4)$ & $145(62.2)$ \\
\hline & $>50$ years & $30(41.1)$ & $85(36.5)$ \\
\hline \multirow[t]{20}{*}{ Country } & Germany & $19(26.0)$ & $36(15.5)$ \\
\hline & The Netherlands & $21(28.8)$ & $29(12.4)$ \\
\hline & Italy & & $23(9.9)$ \\
\hline & Austria & $20(27.4)$ & $20(8.6)$ \\
\hline & UK & $7(9.6)$ & $18(7.7)$ \\
\hline & Belgium & $1(1.4)$ & $14(6.0)$ \\
\hline & Sweden & - & $12(5.2)$ \\
\hline & Japan & - & $10(4.3)$ \\
\hline & France & $1(1.4)$ & $8(3.4)$ \\
\hline & Spain & - & $8(3.4)$ \\
\hline & Iraq & - & $8(3.4)$ \\
\hline & Poland & - & $5(2.1)$ \\
\hline & Ireland & - & $5(2.1)$ \\
\hline & Portugal & - & $5(2.1)$ \\
\hline & Denmark & - & $4(1.7)$ \\
\hline & Switzerland & - & $4(1.7)$ \\
\hline & Turkey & - & $3(1.3)$ \\
\hline & Australia, Greece, India, Canada, USA & - & $2(0.9)$ (per country) \\
\hline & Norway, Malaysia, Denmark, Israel & 1 (1.4) (per country) & - \\
\hline & $\begin{array}{l}\text { Brazil, Finland, Canary Islands, Croatia, Lithuania, Norway, Philippines, } \\
\text { Slovenia, Czech Republic, Cyprus, Egypt }\end{array}$ & - & $1(0.4)$ (per country) \\
\hline \multirow{10}{*}{$\begin{array}{l}\text { Professional education (multiple } \\
\text { answers possible) }\end{array}$} & Medicine & $27(37.0)$ & $155(66.9)$ \\
\hline & Nursing & $21(28.8)$ & $41(17.6)$ \\
\hline & Psycho-oncology & $10(13.7)$ & $25(10.7)$ \\
\hline & Technical support assistant (e.g. medical, radiology) & - & $4(1.7)$ \\
\hline & Patient representatives & $7(9.6)$ & - \\
\hline & IT & $4(5.5)$ & - \\
\hline & Physiotherapy (including sport science) & - & $5(2.1)$ \\
\hline & Occupational therapy & - & $1(0.4)$ \\
\hline & Social service (including social science) & - & $2(0.9)$ \\
\hline & Other & $4(5.5)$ & \\
\hline \multicolumn{2}{|c|}{ Previous experiences with PROs (multiple answers possible ${ }^{1}$ ) } & $n(\%)$ & $n(\%)$ \\
\hline None & & $12(16.4)$ & $66(28.3)$ \\
\hline \multirow[t]{6}{*}{ Research } & & $46(63.0)$ & $130(55.8)$ \\
\hline & $<2$ years & $3(4.1)$ & $2(0.9)$ \\
\hline & $2-5$ years & $16(21.9)$ & $39(16.7)$ \\
\hline & $6-10$ years & $6(8.2)$ & $36(15.5)$ \\
\hline & $11-20$ years & $18(24.7)$ & 34 (14.6) \\
\hline & $>20$ years & $3(4.1)$ & $19(8.2)$ \\
\hline \multirow[t]{6}{*}{ Clinical practice } & & $35(47.9)$ & $101(43.3)$ \\
\hline & $<2$ years & $4(5.5)$ & $8(3.4)$ \\
\hline & $2-5$ years & $11(15.1)$ & $24(10.3)$ \\
\hline & $6-10$ years & $7(9.6)$ & $15(6.4)$ \\
\hline & $11-20$ years & $13(17.8)$ & $25(10.7)$ \\
\hline & $>20$ years & $0(0)$ & $29(12.4)$ \\
\hline Research and practice & & $25(34.2)$ & $102(43.8)$ \\
\hline
\end{tabular}

${ }^{1} n=38$ did not indicate experience with PROs in years 


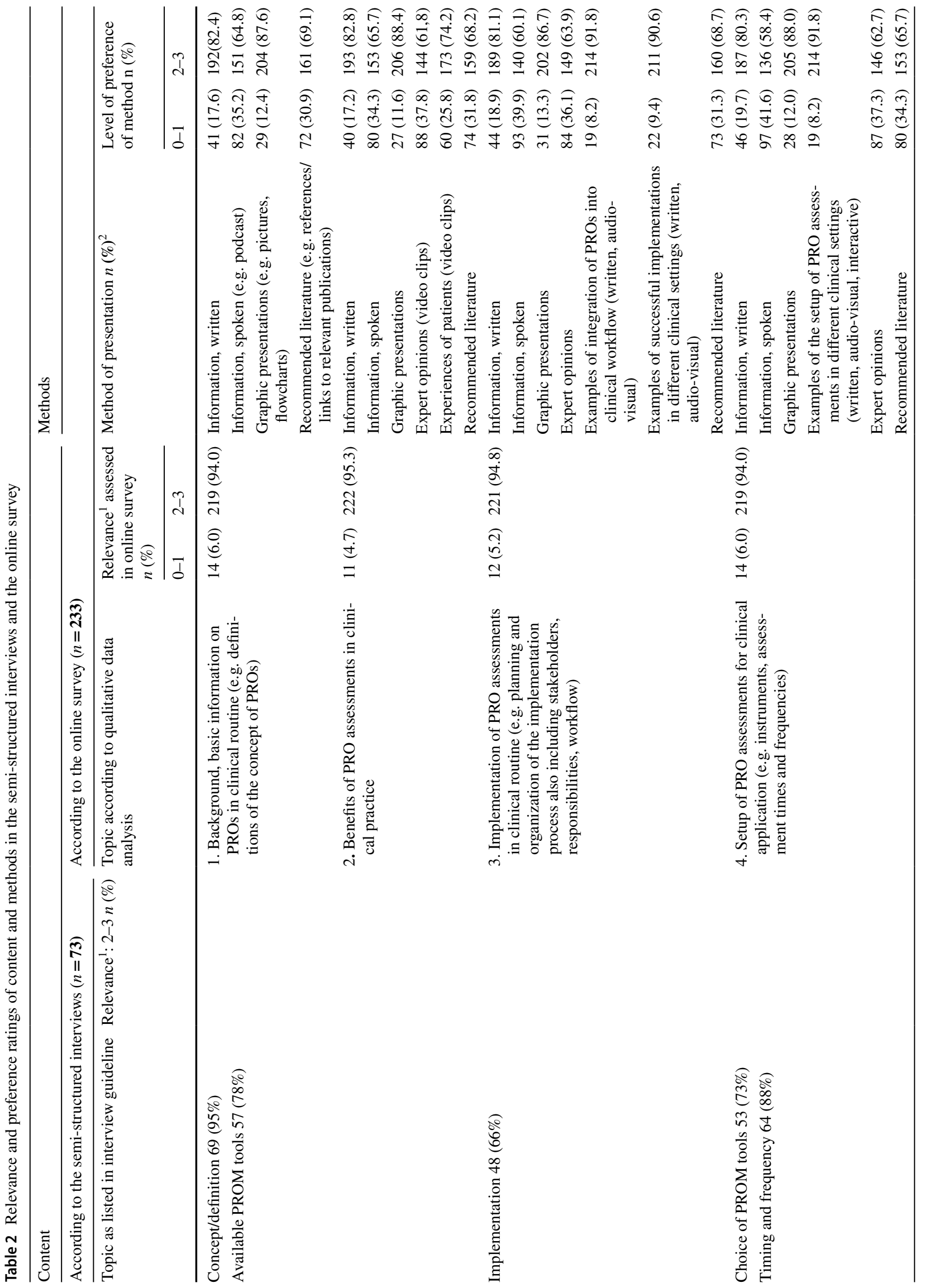




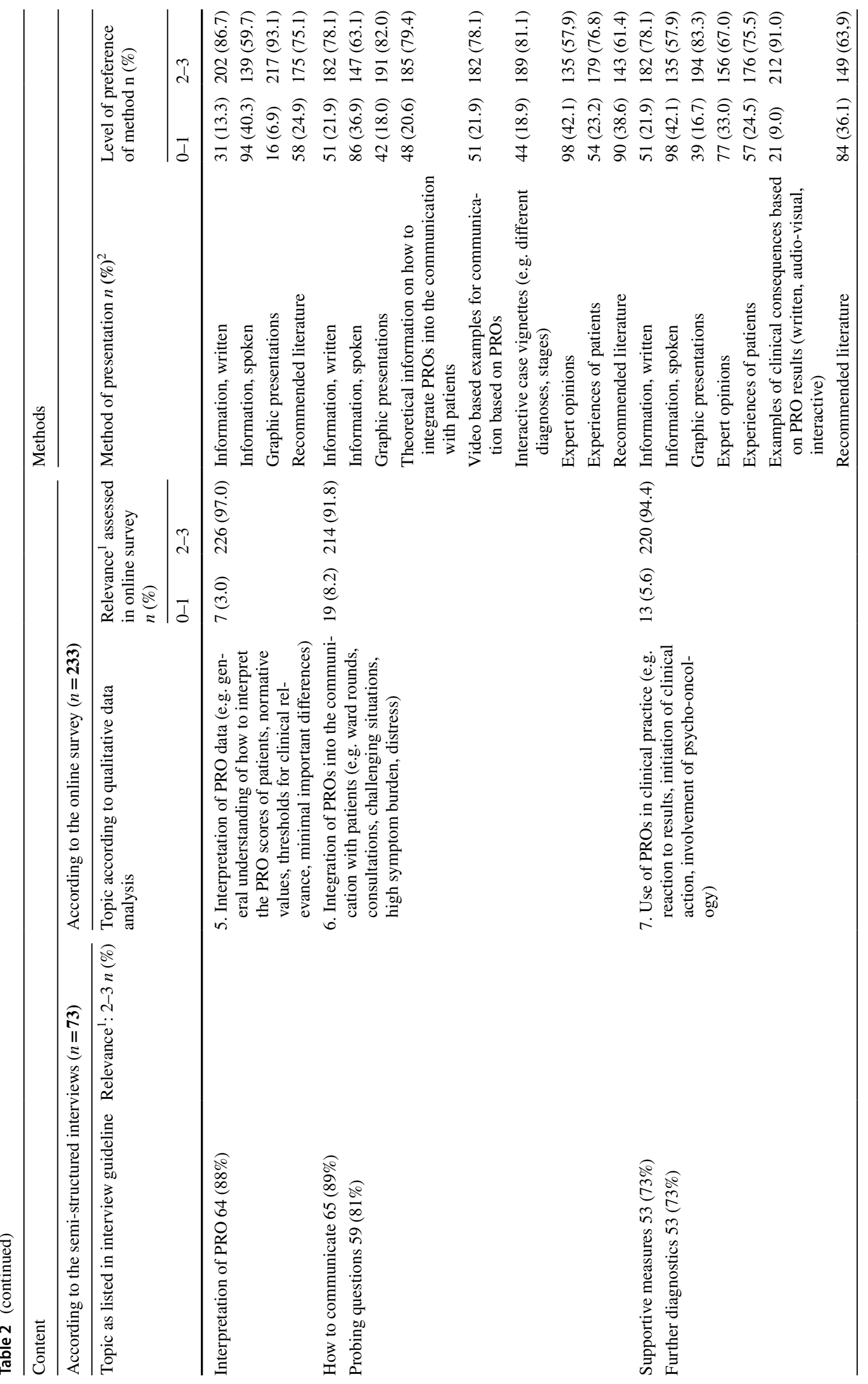




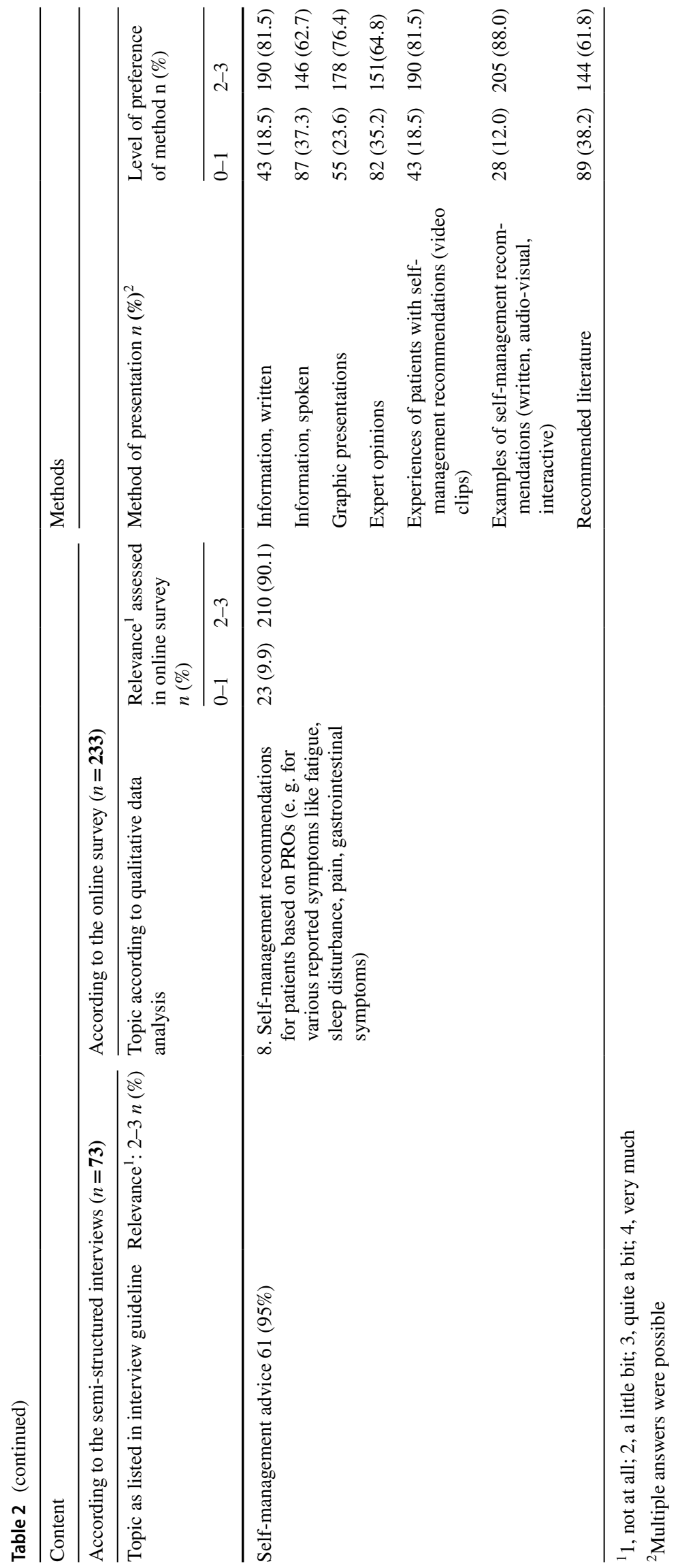


Fig. 1 Joint display of qualitative and quantitative data

\begin{tabular}{l}
\multicolumn{2}{|l|}{ Interview guideline } \\
LEARNING CONTENT
\end{tabular}

Table 3 Final selection of content and methods

\begin{tabular}{|c|c|c|}
\hline & Topic & Methods \\
\hline 1 & Basic information on PROs in clinical routine & Written information, graphics \\
\hline 2 & Benefits of PRO assessments in clinical practice & Written information, graphics \\
\hline 3 & $\begin{array}{l}\text { Implementation of PRO assessments in clinical routine } \\
\text { (including facilitators and barriers) }\end{array}$ & $\begin{array}{l}\text { Written information, graphics } \\
\text { Examples of integration of PROs into clinical workflow } \\
\text { Examples of successful implementations in different clinical } \\
\text { settings (and pitfalls) }\end{array}$ \\
\hline 4 & Setup of PRO assessments for clinical application & $\begin{array}{l}\text { Written information, graphics } \\
\text { Examples of the setup of PRO assessments in different clinical } \\
\text { settings (and pitfalls) }\end{array}$ \\
\hline 5 & Interpretation of PRO data & Written information, graphics \\
\hline 6 & Integration of PROs into the communication with patients & $\begin{array}{l}\text { Written information, graphics } \\
\text { Interactive case vignettes }\end{array}$ \\
\hline 7 & Use of PROs in clinical practice (i.e. PRO-based actions) & $\begin{array}{l}\text { Written information, graphics } \\
\text { Examples of clinical action and pathways based on PRO results }\end{array}$ \\
\hline 8 & $\begin{array}{l}\text { Self-management recommendations for patients based on } \\
\text { PROs }\end{array}$ & $\begin{array}{l}\text { Written information, graphics } \\
\text { Examples of self-management recommendations (and patients } \\
\text { using them: video clips) }\end{array}$ \\
\hline \multicolumn{2}{|c|}{ General and structural aspects } & $\begin{array}{l}\text { Interactive components to enhance knowledge-practice transfer } \\
\text { regarding the use of PROs in clinical practice } \\
\text { blended learning to be considered, depending on structural } \\
\text { possibilities } \\
\text { Certification/accreditation points (if feasible), test of learning } \\
\text { progress }\end{array}$ \\
\hline
\end{tabular}




\section{Learning content}

In the following, each topic section is presented in short. For representative quotes on each section, please refer to Supplementary material file 2 .

\section{Basic information on PROs in clinical routine}

Theoretical knowledge and basic information regarding the concept of PROs, measurement tools and assessment modalities was regarded important in order to reach and inform HCPs, especially those who are new to the field. This includes pointing towards the underlying biopsychosocial model and the importance of including the patient perspective into symptom management for a comprehensive treatment approach.

\section{Benefits of PRO assessments in clinical practice}

Building on basic information, evidence regarding the potential benefits of PRO assessments for clinical practice should be presented and explained to increase motivation to use PROs in clinical practice. Their contribution to a potential survival benefit was judged to be most important to convince oncologists. Additionally, evidence regarding the benefit of PROs for a comprehensive, more structured symptom assessment should be included, even more so in patients reluctant to report their symptoms. Other mentioned areas of benefit are enhanced symptom management, PROs as additional information for treatment planning and facilitation of patient-HCP communication as well as a more active involvement of the patients in decision-making.

3. Implementation of PRO assessments in clinical routine

Participants underlined the importance of addressing the implementation process regarding institutional and individual aspects on different organisational levels (i.e. HCPs with decision-making capacity or in management positions, individual and team perspectives). Implementation issues further included general planning of the implementation of PRO assessments, including costs, resources, stakeholders and technical issues. A stepwise approach for implementation, including identification of and collaboration with motivated colleagues and onsite coaching, was suggested. Awareness of individual and organisational barriers and facilitators (e.g. individual barriers for staff, patient ability and motivation) was described as important. The supporting role of motivated colleagues and senior peers acting as leaders of integration was highlighted.

4. Setup of PRO assessments for clinical application

Considering the setup of PRO assessments, the choice of instruments, timing and frequency (differing with regard to type of disease and treatment phase), emphasising the necessity to keep administrative burden as low as possible was rated to be relevant. The course should also comprise information on available options for electronic data assessment and integration of PRO systems into medical records. Further important aspects to consider when setting up routine PRO assessments include, among others, operative responsibilities, workflow and changes in workflow, interprofessional collaboration including engaging staff in the initial phases of implementation as well as building realistic expectations concerning the time needed to invest.

\section{Interpretation of PRO data}

Regarding practical aspects of PROs like treatment planning and symptom management, participants emphasised that the e-learning course should comprise information on the interpretation of PRO data including a general understanding of how to interpret the PRO scores of patients, normative values, thresholds for clinical relevance and minimal important differences.

6. Integration of PROs into communication with patients

Increased attention should be set on the topic of communicating with patients about PROs on ward rounds, in consultations or in challenging situations such as high symptom burden or distress. Likewise, more specifics on how to proceed with further diagnostic questions on reported symptoms and impairments should also be included in the training.

\section{Use of PROs in clinical practice}

Participants stated the need for recommendations on PRO-based clinical actions for patient-reported symptoms, aiming to make data usable in clinical practice. This may include supportive care options available for specific symptoms or problems such as sexuality and fatigue. Especially nurses emphasised the need for a description of concrete procedures that need to be followed when PRO data warrant clinical action. Also, the consideration of ethical and legal aspects of PRO data assessment in clinical practice should be addressed.

\section{Self-management recommendations for patients} based on PROs

While providing self-management recommendations for various symptoms (e.g. fatigue, sleep disturbances, pain, gastrointestinal symptoms) was reported to be relevant especially in the out-patient setting, the necessity of conveying theoretical understanding of self-management education was also addressed. This includes refining the capacity of HCPs to differentiate between available recommendations and materials in this area to support them in choosing the most suitable tools for their patients.

\section{Structure and didactics of the course} Structure of the e-learning course Participants shared the opinion of the need for tailoring course levels to various learning needs, supporting a modular structure for the e-learning course. 
The importance of usability, including navigation within the programme and easy access, was underlined. Despite the obvious possibilities and advantages of e-learning, awareness of the limitations of this approach, including individual or structural barriers for its use, was deemed important.

Relating to the time frame, interview participants indicated their acceptance for 10-25 min per unit and 1.5-2 $\mathrm{h}$ for the whole programme. Moreover, $52.1 \%$ opted for receiving a certificate if possible or to only receive a certificate when accreditation is provided.

Presentation of learning content With regard to presentation formats, interview data suggested high preference for a combination of methods, such as audio-visual and written information. Correspondingly, in the online survey participants indicated preference for written information $(>78 \%$ in all content categories) and graphical presentation $(>82 \%$ in all content categories, except "self-management"). Participants would highly appreciate a presentation of practical examples of integration of PROs into the clinical workflow (92\%), clinical actions based on PRO data (91\%), successful implementations in different clinical settings (90.6\%) and self-management recommendations (88\%) as well as case vignettes about patients with different diagnoses $(81.1 \%)$. Qualitative comments suggested providing successful best practice examples showing the advantages, feasibility and acceptance of PROs in clinical practice presented by respected peers. Examples of unsuccessful implementations to increase awareness of potential problems and pitfalls were mentioned as well. Additional suggestions for methods of presentation in the online survey included screencasts, webinars and videos.

Interactive components Participants stressed that the course should include interactive components (e.g. regarding the case vignettes, interpretation of data, communication) to facilitate analysing the content and creating individual relevance and enhance knowledge-practice transfer supplemented with options for personal exchange between users and the possibility to combine the e-learning course with face-to face training. Participants would also appreciate options for assessing individual learning progress (e.g. quizz).

\section{Discussion}

This study reports on the first step in developing an e-learning course on the use of EORTC PRO measures for routine PRO assessment targeting oncological health care providers using a user-centred design methodology. Herein, we present the results of the analyses of stakeholder perspectives on learning content and methods.

\section{Preferences for learning content}

With respect to topics that need to be addressed in the e-learning course, HCPs indicated the highest relevance for the interpretation of PRO data, clinical benefits of assessing PRO data, implementation of routine PRO data assessment and the use of PROMs and PRO data in clinical practice. The wish for more standardisation of procedures and increasing the sense of ownership of and the involvement in the process setup was expressed. These results are in line with recent findings on HCPs' perspectives on implementing PROs in routine clinical care in oncology [22-24]. HCPs included in our study recognise the potential to promote earlier intervention and more holistic approaches to oncology care but were concerned about cases when they might feel unable to interpret and adequately respond to the issues identified (e.g. if feasible solutions were unavailable). The need to educate providers about the benefits and value of PROs beyond current clinical approaches and to develop coherent implementation strategies also became apparent [22, 23]. Further implementation aspects raised by participants of our study correspond to key issues reported by Snyder, e.g. goals of assessments, selection of questionnaires, timing and mode of assessments, interpretation of the scores and clinical consequences [24].

The general question of how to motivate other colleagues and decision-makers to opt for routine PRO assessment emerged from most interviews and does generate different answers depending on the respective HCP target group. While a possible survival benefit was reported to be especially motivating for oncologists, standardised care pathways were indicated to support the engagement of nursing professionals. Critical comments emphasised the necessity to address the fundamental question of how PROs, and thus the patient perspective, can be integrated into clinical care in a way that is "actionable" for routine clinical settings. Attitudes towards PROs are often tainted by the fear of losing the human connection with the patient as the centre of physician-patient-interaction, often referred to as empathy [25].

Both the literature and our study show that the following three premises have still not reached the collective knowledge of HCPs, at least in this sample: (1) the patient's perspective is valid, (2) the patient is an important source of subjective symptom information that is otherwise not available, and (3) empathy is an essential aspect in the encounter between people (and therefore also in the clinical encounter). However, a structured measurement of symptom burden will still supplement symptom assessment in the medical interview and allow monitoring over time. This aligns with Stephen [12], stating that when approaching the development of (nursing) curricula, person-centred care should be embedded within several courses and incorporated across the curriculum. According to the latter, areas of interest should include knowledge on how to facilitate PRO assessments, how to 
implement care based on the knowledge gained through PRO data, how to evaluate care based on the feedback given according to PRO data as well as competence in administering PRO instruments, reviewing the following assessments and care planning. Likewise, this should include a balanced presentation of organisational requirements for the adaptation of an effective PRO-based assistance and benefits of the latter for patient outcomes.

\section{Preferences for structure and didactics of the e-learning course}

Considering a digital learning format, HCPs expressed the importance of examples of integration of PROs into the clinical workflow, clinical actions based on PRO data, successful implementations in different clinical settings and self-management recommendations as well as case vignettes about patients with different diagnoses. Integration of examples of successful best practice was suggested but also those of unsuccessful implementations to increase awareness of potential problems and pitfalls. Interactive components such as video examples of simulated consultations with oncologists using PRO data have been previously reported as desired learning formats $[11,13,18]$.

The preferences for a modular approach and tailoring course levels to learning needs were also stated in the context of other digital learning tools where HCPs expressed the importance of a simple and visually attractive e-learning environment with a combination of (evidence-based) theory, modelling videos and illustrations [18]. Different HCP target groups with differing clinical obligations, service settings and associated fields of interest might require different content foci, e.g. general planning and organisation of the implementation process, including awareness of structural barriers and limited resources, might be more interesting for HCPs who are in a position to decide on and plan implementations.

\section{Strengths and limitations}

Strengths of the project are the stepwise design comprising a scoping review of the relevant literature, qualitative interviews and the online survey resulting in quantitative data, corresponding to the "CeHRes Roadmap" for the development of eHealth technologies [16-18]. The high participation rate enabled a rich qualitative and quantitative database. The purposeful sampling provided perspectives of professionals of various professional backgrounds as recommended [16]. The international sample of the online survey allowed a more detailed insight and interpretation of the results for the intended international target population, differing in their level of familiarity with and expertise in assessment and interpretation of PROs and different health care systems.

\section{Conclusion}

Educational needs regarding knowledge of and competences in the integration of PROs in communication and clinical care became evident, implying possible different foci of learning content and topics of interest across levels of clinical engagement. Data imply HCPs' wish for more standardisation of clinical procedures of PRO assessment and initiation of PRO-based clinical pathways. The importance of concrete examples of integration of PRO systems and clinical use based on PRO data was highlighted. Regarding e-learning methodology, the modular approach and interactive case-based examples were considered important features.

Supplementary Information The online version contains supplementary material available at https://doi.org/10.1007/s00520-021-06676-x.

Acknowledgements We would like to thank all study participants for contributing their time, perspective and expertise to the study. We thank the following organisations for distributing the online survey: British Psychosocial Oncology Society (BPOS), National Cancer Research Institute (NCRI), UK Oncology Nursing Society (UKONS), The Dutch Neuro-Oncology Working Group, Psychosocial Oncology Working Group of the Dutch Cancer Society, Arbeitsgemeinschaft hämatologischer und onkologischer Pflegender, Austrian Psychooncology Platform (ÖPPO), German Cancer Society (DKG), Working Group for Supportive Therapy (AGSMO), Regional Cancer Society, Quality of Life Group of German Radio-oncologists (DEGRO), German Oncology Nursing Society, International Society of Geriatric Oncology (SIOG) and the EORTC Quality of Life Department.

Author contribution MS, LMW, SR and HS wrote the manuscript, designed the study, conducted the literature search and review, coordinated data collection, assessed and analysed the data. LD, IVdL and TN designed the study, assessed and analysed data and edited the manuscript. GV, MT, AB, DK and TK designed the study, analysed the data and edited the manuscript. All authors read, edited and approved the final version of the manuscript.

Funding Open access funding provided by University of Innsbruck and Medical University of Innsbruck. The study was funded by the EORTC Quality of Life Group (grant number 001-2019).

Availability of data and material Data is available upon request.

Code availability Not applicable.

\section{Declarations}

Ethics approval Each participating centre adhered to the requirements of their local ethic committees.

Consent to participate Informed consent was obtained from all individual participants included in the study, according to the local requirements.

Consent for publication Informed consent was obtained from all individual participants included in the study, according to the local requirements. 
Conflict of interest The authors disclose any financial and personal relationships with other people or organisations that could inappropriately influence this study.

Open Access This article is licensed under a Creative Commons Attribution 4.0 International License, which permits use, sharing, adaptation, distribution and reproduction in any medium or format, as long as you give appropriate credit to the original author(s) and the source, provide a link to the Creative Commons licence, and indicate if changes were made. The images or other third party material in this article are included in the article's Creative Commons licence, unless indicated otherwise in a credit line to the material. If material is not included in the article's Creative Commons licence and your intended use is not permitted by statutory regulation or exceeds the permitted use, you will need to obtain permission directly from the copyright holder. To view a copy of this licence, visit http://creativecommons.org/licenses/by/4.0/.

\section{References}

1. FDA (2006) Guidance for industry: patient-reported outcome measures: use in medical product development to support labeling claims: draft guidance. Health Qual Life Outcomes 4:79

2. Gilbert A, Sebag-Montefiore D, Davidson S, Velikova G (2015) Use of patient-reported outcomes to measure symptoms and health related quality of life in the clinic. Gynecol Oncol 136(3):429-439

3. Kotronoulas G, Kearney N, Maguire R, Harrow A, Di Domenico D, Croy S, MacGillivray S (2014) What is the value of the routine use of patient-reported outcome measures toward improvement of patient outcomes, processes of care, and health service outcomes in cancer care? A systematic review of controlled trials. J Clin Oncol 32(14):1480-1501

4. Denis F, Basch E, Septans AL, Bennouna J, Urban T, Dueck AC, Letellier C (2019) Two-year survival comparing web-based symptom monitoring vs routine surveillance following treatment for lung cancer. JAMA 321(3):306-307

5. Basch E, Deal AM, Kris MG, Scher HI, Hudis CA, Sabbatini P, Rogak L, Bennett AV, Dueck AC, Atkinson TM et al (2016) Symptom monitoring with patient-reported outcomes during routine cancer treatment: a randomized controlled trial. J Clin Oncol 34(6):557-565

6. Basch E, Deal AM, Dueck AC, Scher HI, Kris MG, Hudis C, Schrag D (2017) Overall survival results of a trial assessing patient-reported outcomes for symptom monitoring during routine cancer treatment. JAMA 318(2):197-198

7. Porter I, Goncalves-Bradley D, Ricci-Cabello I, Gibbons C, Gangannagaripalli J, Fitzpatrick R, Black N, Greenhalgh J, Valderas JM (2016) Framework and guidance for implementing patientreported outcomes in clinical practice: evidence, challenges and opportunities. J Comp Eff Res 5(5):507-519

8. Voutilainen A, Saaranen T, Sormunen M (2017) Conventional vs. e-learning in nursing education: a systematic review and metaanalysis. Nurse Educ Today 50:97-103

9. Sinclair PM, Kable A, Levett-Jones T, Booth D (2016) The effectiveness of Internet-based e-learning on clinician behaviour and patient outcomes: a systematic review. Int J Nurs Stud 57:70-81

10. Lahti M, Hatonen H, Valimaki M (2014) Impact of e-learning on nurses' and student nurses knowledge, skills, and satisfaction: a systematic review and meta-analysis. Int J Nurs Stud 51(1):136-149

11. Santana MJ, Haverman L, Absolom K, Takeuchi E, Feeny D, Grootenhuis M, Velikova G (2015) Training clinicians in how to use patient-reported outcome measures in routine clinical practice. Qual Life Res

12. Stephen $T$ (2019) Integrating quality of life assessments in student clinical learning experience. Qual Adv Nurs Educ

13. Absolom K (2014) Using a patient-reported outcome measure in chemotherapy review consultations: the impact of an interactive doctor training session. In.

14. Bausewein C, Simon ST, Benalia H, Downing J, Mwangi-Powell FN, Daveson BA, Harding R, Higginson IJ (2011) Implementing patient reported outcome measures (PROMs) in palliative careusers' cry for help. Health Qual Life Outcomes 9:27

15. Ly JJ, Crescioni M, Eremenco S, Bodart S, Donoso M, Butler AJ, Dallabrida SM (2019) Training on the use of technology to collect patient-reported outcome data electronically in clinical trials: best practice recommendations from the ePRO Consortium. Ther Innov Regul Sci 53(4):431-440

16. van Gemert-Pijnen JE, Nijland N, van Limburg M, Ossebaard HC, Kelders SM, Eysenbach G, Seydel ER (2011) A holistic framework to improve the uptake and impact of eHealth technologies. $\mathrm{J}$ med Internet res 13(4):e111

17. Stuij SM, Drossaert CHC, Labrie NHM, Hulsman RL, Kersten MJ, van Dulmen S, Smets EMA (2020) group Ip: Developing a digital training tool to support oncologists in the skill of information-provision: a user centred approach. BMC Med Educ 20(1): 135

18. Stuij SM, Labrie NHM, van Dulmen S, Kersten MJ, Christoph N, Hulsman RL, Smets E (2018) group Ip: Developing a digital communication training tool on information-provision in oncology: uncovering learning needs and training preferences. BMC Med Educ 18(1):220

19. Patton MQ (2002) Qualitative research and evaluation methods, 3rd edn. Sage, Thousand Oaks

20. Mayring P (2010) Qualitative Inhaltsanalyse. In: Handbuch Qualitative Forschung in der Psychologie. edn. Edited by Mey G. MK: VS Verlag für Sozialwissenschaften

21. Guetterman TC, Fetters MD, Creswell JW (2015) Integrating quantitative and qualitative results in health science mixed methods research through joint displays. Ann Fam Med 13(6):554-561

22. Wohlfahrt P, Zickmund SL, Slager S, Allen LA, Nicolau JN, Kfoury AG, Felker GM, Conte J, Flint K, DeVore AD et al (2020) Provider perspectives on the feasibility and utility of routine patient-reported outcomes assessment in heart failure: a qualitative analysis. J Am Heart Assoc 9(2): e013047

23. Litchfield I, Greenfield S, Turner GM, Finnikin S, Calvert MJ (2021) Implementing PROMs in routine clinical care: a qualitative exploration of GP perspectives. BJGP Open

24. Snyder CF, Aaronson NK, Choucair AK, Elliott TE, Greenhalgh J, Halyard MY, Hess R, Miller DM, Reeve BB, Santana M (2012) Implementing patient-reported outcomes assessment in clinical practice: a review of the options and considerations. Qual Life Res 21(8):1305-1314

25. NicGiollaEaspaig B, Tran Y, Bierbaum M, Arnolda G, Delaney GP, Liauw W, Ward RL, Olver I, Currow D, Girgis A et al (2020) What are the attitudes of health professionals regarding patient reported outcome measures (PROMs) in oncology practice? A mixed-method synthesis of the qualitative evidence. BMC Health Serv Res 20(1):102

Publisher's note Springer Nature remains neutral with regard to jurisdictional claims in published maps and institutional affiliations. 


\section{Authors and Affiliations}

Monika Sztankay ${ }^{1}$ (D) Lisa M. Wintner ${ }^{1} \cdot$ Sigrid Roggendorf $^{3} \cdot$ Thomas Nordhausen $^{3} \cdot$ Linda Dirven $^{4,5}$.

Martin J. B. Taphoorn ${ }^{4,5} \cdot$ Irma M. Verdonck-de Leeuw ${ }^{6,7}$. Galina Velikova ${ }^{8,9} \cdot$ Andrew Bottomley $^{10} \cdot$ Dagmara Kulis $^{10}$. Timo Kachel ${ }^{2} \cdot$ Heike Schmidt $^{3,11}$ - on behalf of the EORTC Quality of Life Group

1 University Hospital of Psychiatry II, Medical University of Innsbruck, Anichstrasse 35, Innsbruck, Austria

2 University Hospital of Psychiatry I, Medical University of Innsbruck, Innsbruck, Austria

3 Institute for Health and Nursing Science, Medical Faculty, Martin Luther University Halle-Wittenberg, Halle, Germany

4 Department of Neurology, Leiden University Medical Center, Leiden, The Netherlands

5 Department of Neurology, Haaglanden Medical Center, The Hague, The Netherlands

6 Department of Otolaryngology-Head and Neck Surgery, Amsterdam University Medical Centers (Location VUmc), Amsterdam UMC, Vrije Universiteit Amsterdam, Cancer Center Amsterdam, Amsterdam, The Netherlands
7 Faculty of Behavioural and Movement Sciences, Section Clinical Psychology, Amsterdam Public Health, Amsterdam, The Netherlands

8 Leeds Institute of Medical Research at St James's, University of Leeds, Leeds, UK

9 Leeds Cancer Centre, St James's University Hospital, Leeds, UK

10 European Organisation for Research and Treatment of Cancer (EORTC), Quality of Life Department, Brussels, Belgium

11 Department for Radiation Medicine, University Hospital Halle (Saale), Halle, Germany 